\title{
Las voces de educadoras de nivel maternal: retos profesionales
}

\author{
YAMILETH BOLAÑOS MARTÍNEZ* \\ Universidad Icesi (Cali, Colombia)
}

OSPINA, V., CALDERÓN, T., QUINTERO, M., CANTOR, J. y VILLALOBOS, M. (2018). El rol del educador del nivel maternal. Tensiones y debates. Cali: Editorial Bonaventuriana/ Universidad Icesi. 132 págs.

El libro El rol del educador del nivel maternal. Tensiones y debates surge del proyecto de investigación «La formación de agentes educativos y el cuidado de niños en los primeros 18 meses de vida. Una propuesta centrada en la subjetivación», desarrollado en conjunto por profesoras de las Universidades San Buenaventura (Cali), Icesi y del Valle. Este proyecto se preguntó por el rol que asumen las y los adultos cuidadores y los retos en la formación docente derivados de la llegada, cada vez más pronto, de niños y niñas durante sus primeros meses de vida-momentos claves en su constitución subjetiva- a instituciones educativas.

Las autoras, mediante una metodología de acción-participación, realizaron un seminario de formación docente en el que se les dio voz a trece maestras de seis instituciones educativas públicas y privadas de la ciudad de Cali, en el cual se implementaron recursos pedagógicos como: mesas de conversación, realimentación a registros fílmicos de prácticas educativas y trabajo desde experiencias sensibles. De esta forma, este libro busca constituirse, no en un manual de líneas metodológicas para la formación docente, sino en un referente de consulta acerca de las bases teóricas que se pusieron a prueba en las conversaciones con las maestras sobre los interrogantes y tensiones que atraviesan en el ejercicio de su rol actual.

\footnotetext{
*Email:yami920603@hotmail.com
} 
En términos de su estructura, el libro inicia con un apartado preliminar en donde se explicitan los principios rectores del seminario; y continúa con un segundo apartado que detalla la metodología de trabajo llevada a cabo con las maestras. En este apartado, las autoras exponen también que partieron desde una perspectiva de la práctica reflexiva y del paradigma crítico reflexivo para permitir que las maestras tomaran distancia frente a sus propias intervenciones, y se cimentara una relación de intercambio y construcción de conocimiento mutuo, lejos de la relación vertical de investigador-investigado. En esta relación de colaboración y respeto, las autoras buscaban permitir que las maestras se asumieran como responsables de su quehacer cotidiano con los niños y como interlocutoras, antes que plantear y desarrollar unos presupuestos conceptuales.

Posteriormente, el libro presenta tres capítulos, cada uno inicia con un componente teórico y finaliza con notas de trabajo de campo. El primero ellos, «Maternar o educar a los más pequeños en las instituciones», inicia con una discusión en torno al maternaje y a su diferenciación de otras funciones de cuidado con los niños, como la educativa. Maternar implica cumplir funciones que social e históricamente se han asignado a la madre, que propician la configuración de funciones psicológicas primordiales. Posteriormente, surge una pregunta sobre la posibilidad de constitución subjetiva de las y los niños en sus primeros meses de vida en entornos institucionales como la escuela. De acuerdo con las autoras, las maestras de maternal requieren del desarrollo de una sensibilidad especial para conectarse con los niños y las niñas que difiere del vínculo educativo formal que tradicionalmente se ha dado en las escuelas. Esta sensibilidad permite que las maestras ofrezcan intercambios maternales que no suplen la labor materna porque se enmarcan en un vínculo laboral, pero que sí contribuyen en la constitución subjetiva de las y los niños más pequeños.

En el trabajo de campo las maestras compartieron su asombro y preguntas frente a su nuevo rol como educadoras maternales, además de su angustia frente a no saber qué hacer en momentos en los que su formación pedagógica resultaba insuficiente para responder a los requerimientos de las y los niños más pequeños. Adicionalmente, emergen diferentes tensiones entre las familias y la escuela maternal porque aparecen metas y valores de crianza encontrados. Las autoras sugieren que en la formación de las maestras debería ser posible reinventar la relación familia-institución para valorizar tanto saberes culturales provenientes de las familias como saberes institucionales, y que ambas partes reconozcan que el proceso de crianza de los niños más pequeños es compartido.

En el segundo capítulo, «La crianza de los más pequeños ¿Un asunto de comunidad, familia o Estado?», las autoras-desde una perspectiva cultural del desarrollo de los niños-se distancian de miradas que plantean ideales de desarrollo o prácticas de 
crianza universales. En este apartado se resaltan los desafíos que despierta el cambio histórico actual en la crianza, al ser asumida, desde muy temprano, por las escuelas maternales. En esta vía, la pregunta que rondó durante el trabajo de campo indagó sobre la posibilidad de una vida cotidiana en el maternal, teniendo en cuenta que en la escuela maternal los niños más pequeños requieren, antes de volverse aprendices de la escuela, llegar a ser humanos. El reto asumido por la escuela maternal sería idear una manera de devolver el valor de los intercambios cotidianos con los niños, en los que ellos puedan configurar su mundo subjetivo y sean visibles de forma diferenciada y particular por sus maestras, por encima de las propuestas heredadas del proyecto educativo moderno que oferta a las y los niños una educación universal y estructurada por vía de la disciplina.

El tercer capítulo se titula «El cuerpo, la corporalidad y las intervenciones corporales en la infancia». En este apartado las autoras señalan cómo en la historia de las instituciones educativas ha prevalecido una mirada del cuerpo escindido de la mente y relegado al lugar del ejercicio y la repetición de movimientos. Esta mirada es heredada por las escuelas maternales que aparecen como primer eslabón educativo, aunque ello pueda generar un riesgo: que las exigencias hechas a los cuerpos de los niños escolarizados - como la corrección postural o el control de la atención- que reproducen formas mecánicas de organización corporal, se desplacen al nivel maternal limitando la experiencia corporal creadora y sensible en los primeros años de los niños. Las autoras exponen nuevas miradas no dualistas de cuerpo y mente, de la mano del concepto de corporalidad como una dimensión de experiencia singular que cada individuo y grupo cultural entabla con su cuerpo a lo largo de la vida. Así, la corporalidad es descubierta por el niño o la niña y el juego corporal aparece como uno de los recursos que permiten construir la dimensión de agencia de niños y niñas.

El trabajo de campo en este apartado permitió que las maestras percibieran su dimensión corporal y las relaciones que establecen con los niños. Además, las llevó a una confrontación entre el reconocimiento de las necesidades particulares de niños y niñas y el cumplimiento de disposiciones institucionales. Al final, el rol de maestra de nivel maternal se encuentra entre aquel lugar de distancia y rigor promovido por la escuela, y el lugar de cercanía y afecto de la madre. Por ello, el énfasis en el trabajo con las maestras no estaba en la planeación de actividades pedagógicas sino en la observación de los niños y la reflexión sobre cómo las intervenciones de las educadoras de maternal habilitan a las y los niños para hacer cosas por sí mismos.

En las conclusiones las autoras resaltan el incremento en Colombia del nivel maternal, aunado a diferentes críticas existentes en Latinoamérica respecto a la formación de educadores de este nivel. Por eso plantean la necesidad de crear espacios de construcción de conocimiento en los que sea posible dar voz a las 
maestras de maternal, lejos del paradigma tradicional de valorización del conocimiento académico por encima de saberes comunitarios. La academia entonces está llamada a acompañar a las educadoras de maternal en su construcción de una nueva identidad profesional que se ubique entre el lugar profesional y el lugar de las familias. Lo anterior porque las y los niños al constituirse como seres humanos requieren de educadoras que puedan desplegar habilidades de parentalidad intuitiva y reconocerse como sujetos de saber que hacen modificaciones a sus prácticas cuando lo consideran necesario. La idea es configurar el nivel maternal evitando la extrapolación del formato de preescolar y de sus prácticas.

El libro incursiona en un tema novedoso e importante en Colombia como el de la institucionalización de los niños más pequeños desde la mirada de las educadoras de maternal. La institucionalización ha sido abordada antes para niños, niñas y adolescentes (NNA) que no cuentan con el cuidado de sus padres y desde ahí se ha promovido su erradicación, en la vía de propiciar programas y políticas que prevengan el abandono de NNA, desde una perspectiva que reconoce a la familia como la institución socialmente legitimada para ejercer la labor de crianza (Palummo, 2013). Sin embargo, en este nuevo escenario planteado por Ospina, Calderón, Quintero, Cantor y Villalobos (2018) se abre una discusión alrededor de la necesidad de adaptación frente a las trasformaciones del mundo del trabajo que deben afrontar instituciones como la escuela, caracterizadas por su resistencia al cambio, para lograr acoger niños y niñas en sus primeros años de vida, en un trabajo de crianza en conjunto con sus familias.

El libro se organiza de forma innovadora al presentar sus principios rectores en las dimensiones ontológica, ética, estética y política; además, antes de presentar los tres capítulos, las autoras exponen un detallado apartado metodológico que permite al lector tener claridad frente a lo desarrollado en las sesiones del seminario. Lo anterior es coherente con los propósitos del texto: ser una provocación para el lector y un llamado a pensar en el rol de educador o educadora maternal teniendo en cuenta, antes que los saberes pedagógicos, la sensibilidad para contribuir a que un bebé llegue a ser humano.

Se destaca, especialmente, aquel planteamiento de las autoras en el que introducen un entendimiento de los niños y niñas más pequeños como sujetos cuyo desarrollo no se encuentra escindido en desarrollo social, motriz y emocional, sino que se habla de los niños y las niñas como seres corporales en proceso de construcción de sí mismos. Lo anterior tiene incidencias en las intervenciones de las educadoras de maternal, específicamente en su forma de observar a los y las niñas. Esta nueva mirada es un reto no menor, ya que implica emprender una cruzada en tensión con la tradición de Occidente que escinde al ser humano en mente y cuerpo. 


\section{Referencias}

PALUMMO, J. (2013). La situación de niños, niñas y adolescentes en las instituciones de protección y cuidado de América Latina y el Caribe. Panamá: UNICEF. 